\title{
REFERENCIAL CURRICULAR AMAZONENSE: APONTAMENTOS SOBRE EDUCAÇÃO AMBIENTAL E POSSÍVEIS TRANSGRESSÕES
}

\author{
AMAZONIAN CURRICULAR REFERENCE: NOTES ON \\ ENVIRONMENTAL EDUCATION AND POSSIBLE TRANSGRESSIONS
}
REFERENCIA CURRICULAR DE AMAZON: NOTAS SOBRE LA EDUCACION AMBIENTAL Y POSIBLES TRANSGRESIONES

\author{
Rafaella Bruno Antunes de Souza ${ }^{1}$ (D) 9 \\ Mônica de Oliveira $\operatorname{Costa}^{2}$ (D) 9
}

\begin{abstract}
RESUMO
Este artigo é um esforço de problematizar os modos de ver e dizer a Educação Ambiental no Referencial Curricular Amazonense (2019). Tal documento surge de uma suposta necessidade de se elencar os conteúdos ditos corretos/adequados para serem ensinados aos estudantes, no período pósimplementação da Base Nacional Comum Curricular (2017). Dessa maneira, alinhando-nos a Michel Foucault, procuramos realizar uma análise genealógica que apresenta os enunciados atrelados aos marcos conceituais da Educação Ambiental, partindo da premissa de que isto revela o contexto histórico, dá possibilidades de existência e indica possíveis brechas. Dessa forma, a investigação mostra considerações a respeito do Referencial Curricular Amazonense com o objetivo de vislumbrar possibilidades de transgressão e construção de currículos advindos de uma docência cotidiana.
\end{abstract}

Palavras-chave: Formação de professores. Subjetividade. Currículo. Base Nacional Comum Curricular. Michel Foucault.

\begin{abstract}
This article is an effort to problematize the ways of seeing and saying Environmental Education in the Amazonian Curriculum Framework (2019). Such a document arises from an allegedlyneed to list the contents said to be correct / adequate to be taught to students, in the post-implementation period of the Common National Curricular Base (2017). Thus, aligning ourselves with Michel Foucault, we seek to perform a genealogical analysis that presents the statements linked to the conceptual framework of Environmental Education, based on the premise that this reveals the historical context, gives possibilities of existence and indicates possible gaps. In this way, the investigation shows considerations regarding the Amazonian Curriculum Reference in order to glimpse possibilities of transgression and construction of curricula that comes from daily teaching.
\end{abstract}

Keywords: Teacher training. Subjectivity. Curriculum. Common National Curricular Base. Michel Foucault.

\footnotetext{
${ }^{1}$ Graduada em Licenciatura Plena em Ciências Naturais pela Universidade Federal do Amazonas - UFAM. Mestranda em Educação e Ensino de Ciências na Amazônia pela Universidade do Estado do Amazonas - UEA, Manaus, Amazonas, Brasil. Endereço para correspondência: Av. Djalma Batista, 2470, Chapada, Manaus, Amazonas, Brasil, 69050-010. E-mail: rbads.mca19@uea.edu.br.

${ }^{2}$ Doutora em Educação em Ciências pela Reamec. Professora na Universidade do Estado do Amazonas - UEA, Manaus, Amazonas. Endereço para correspondência: Av. Djalma Batista, 2470, Chapada, Manaus, Amazonas, Brasil, 69050-010. E-mail: mdcosta@uea.edu.br.
}

Universidade Federal de Mato Grosso, Cuiabá, Mato Grosso, Brasil. Revista REAMEC - Rede Amazônica de Educação em Ciências e Matemática, v. 9, n. 1, e21017, janeiro-abril, 2021. 


\section{RESUMEN}

Este artículo es un esfuerzo por problematizar las formas de ver y decidir la educación ambiental en la Referencia Curricular Amazónica (2019). Este documento surge de una supuesta necesidad de enumerar las convocatorias de contenido correcto / apropiado que se le dará a los estudiantes, en el período posterior a la implementación de la Base Común de Currículos Nacionales (2017). Entonces, en la línea de Michel Foucault, intentamos realizar un análisis genealógico que presente los enunciados vinculados a los marcos conceptuales de la Educación Ambiental, partiendo de la premisa de que revela el contexto histórico, las posibilidades de existencia e indica posibles lagunas. Como tal, la investigación investiga consideraciones sobre el Currículo de Referencia Amazónico con el objetivo de predecir posibilidades de transgresión y construcción de planos de estudio derivados de una educación diaria.

Palabras clave: Formación docente. Subjetividad. Plan de estudios. Base Curricular Nacional Común. Michel Foucault.

\section{PRIMEIRAS PALAVRAS}

Borboletas me convidaram a elas. O privilégio insetal de ser uma borboleta me atraiu. Por perto eu iria ter uma visão diferente dos homens e das coisas. Eu imaginava que o mundo visto de uma borboleta seria, com certeza, um mundo livre de pernas, Daquele ponto de vista: Vi que as árvores são mais competentes em auroras do que os homens. Vi que as tardes são mais aproveitadas pelas garças do que pelos homens.

Vi que as águas têm mais qualidade para a paz do que os homens.

Vi que as andorinhas sabem mais das chuvas do que os cientistas. Poderia narrar muitas coisas, ainda que pude ver do ponto de vista de uma borboleta. Ali até o meu fascínio era azul. Manoel de Barros, 2000.

Na obra Ensaios Fotográficos, de Manoel de Barros (2000), há um convite para olharmos o mundo pela perspectiva das borboletas. Podemos perceber que o autor nos revela um olhar sensível e de um outro ângulo que não o da centralidade e da legalidade. Com efeito, utilizando esta sensibilidade de apreensão do mundo ao nosso redor, podemos perceber as coisas miúdas e singulares.

Destarte, este artigo é uma dessas coisas miúdas e apresenta um recorte de uma dissertação de mestrado que busca problematizar os modos de ver e dizer a Educação Ambiental, doravante EA, nos anos finais do Ensino Fundamental, de uma Secretaria de Ensino do Estado do Amazonas.

Ela foi trilhada numa abordagem foucaultiana, analisando os discursos que emergem do documento oficial escolhido para a análise, o Referencial Curricular Amazonense - RCA, na 
tentativa de apontar os enunciados atrelados aos marcos conceituais da EA. Em outras palavras, partindo da premissa de tal estudo, visamos mostrar o contexto histórico que dá possibilidades de existência de tais enunciados, na mesma medida em que indica possíveis brechas no desenvolvimento deles.

Assim, observaremos as discussões que se encontram atreladas ao discurso ambiental escolar, acionando o dispositivo da EA, principalmente pelo forte apelo da mídia e relacionado à Crise Ambiental do Planeta. Isso nos chama atenção para o problema e institui modos para salvar o planeta Terra. Logo, somos levados a pensar na nossa responsabilidade individual e coletiva para o bem da vida frente à finitude dos recursos naturais.

Nesse sentido, Carvalho (2012) expõe que essa questão é atribuída à formação do sujeito ecológico, já que os processos para o formar passam pelo movimento ecológico e pela própria EA. Com essa suposta conscientização acerca dos problemas ambientais, percebemos que os mesmos passam a conquistar adeptos para um novo estilo de vida. Em outras palavras, como revela Carvalho (2012, p. 65), esse modo ideal de ser e viver orientado pelos princípios do ideário ecológico é o que chamamos de sujeito ecológico.

É nessa perspectiva que olhamos para Referencial Curricular Amazonense, doravante RCA como formatação de modos de ver e dizer a Educação Ambiental para professores, estudantes e todos os envolvidos no processo de ensino e aprendizagem. Ele foi elaborado no início da implementação da Base Nacional Comum Curricular, doravante BNCC, seguindo a mesma lógica neoliberal de impor de cima para baixo as determinações legais para a educação no Brasil.

Entendemos que é necessário um olhar crítico para o RCA, uma vez que se alinha aos ideários educacionais, políticos, sociais e econômicos da BNCC, no sentido de que se nos mostra como coisa-feita, pois produz comportamentos.

Nesse sentido, Corazza (2016, p. 142) se pergunta, acerca da autonomia do docente, "se a base, no modo como está expressa e organizada, não levaria os professores, mais uma vez, à posição passiva de consumidores de um currículo [...]”. Ou seja, ela desconsideraria os docentes sujeitos imprescindíveis das reflexões e organizações do processo educativo.

Assim sendo, com o objetivo de problematizar as verdades sobre a Educação Ambiental contidas nesse documento, usamos as ferramentas foucaultianas do enunciado, discurso e relações de poder-saber na intenção de identificar e discutir os enunciados que delineiam o marco conceitual da Educação Ambiental no Amazonas. 


\title{
2 EDUCAÇÃO AMBIENTAL COMO PRÁTICA DE FORMAÇÃO DE DISCURSO
}

Um currículo pode ser considerado um território a procura da ordem, de instituições, de conteúdos, de estruturas, porque isso faz parte de um jogo dentro do próprio currículo em que se constituem os modos de vida. Em outras palavras:

\begin{abstract}
Um currículo é diferença por natureza; é pura diferença; é diferença em si. Afinal, é um território de multiplicidades de todos os tipos, de disseminação de saberes diversos, de encontros "variados", de composições "caóticas", de disseminações "perigosas", de contágios "incontroláveis", de acontecimentos "insuspeitados". Um currículo é, por natureza, rizomático, porque é território de proliferação de sentidos e multiplicação de significados. Apesar de todos os poderes que fazem o controle, demarcam as áreas, e opinam sobre como evitar a desorganização em um currículo e que demandam sua formatação, tudo vaza e escapa (PARAÍSO, 2010, p. 588).
\end{abstract}

Em conformidade com Paraíso, assumimos que o currículo precisa ser compreendido a partir das teorias pós-estruturalista que o concebem como linguagem. Nesse currículo, iremos identificar significantes, significados, conceitos, falas, posições do discurso, fabricações de modos de ver. Dessa maneira, essa compreensão nos permite afirmarmos que o currículo produz os sujeitos e como nós conceituamos as coisas. Veiga-Neto $(2014$, p. 89) explica que:

Em vez de ver a linguagem como um instrumento que liga o nosso pensamento à coisa pensada, ou seja, como um instrumento de correspondência e como formalização da arte de pensar, Foucault assume a linguagem como constitutiva do nosso pensamento e, em consequência, do sentido que damos às coisas, à nossa experiência, ao mundo.

Assim, compreendemos que a linguagem produz verdades sobre a EA e se materializa de várias formas para ensinar os modos corretos de se relacionar com o ambiente. Com efeito, devemos entender "que um currículo, como linguagem, é uma prática social, discursiva e não discursiva, que se corporifica em instituições, saberes, normas, prescrições morais, regulamentos, programas, relações, valores, modos de ser sujeito" (CORAZZA, 2002, p. 10).

Essa ideia de currículo está baseada na perspectiva da Análise do Discurso. Logo, a fim de compreender essa dimensão, Revel (2011, p. 41) esclarece-nos que o discurso é "um conjunto de enunciados que podem pertencer a campos diferentes, mas que obedecem - apesar de tudo - às regras de funcionamento comuns." Contudo, fica claro que não são somente regras linguísticas ou formais, mas que irão reproduzir uma série de divisões históricas estabelecidas pela ordem do discurso específica de cada período, objetivando uma função de normas e reguladora para os mecanismos de organização que se dão através da produção de saberes, práticas e estratégias. 
Nesse ínterim, Foucault (2008) afirma que no interior dos discursos ocorre uma busca pelas unidades formadoras dos mesmos, o que pode ser chamada descrição dos acontecimentos discursivos, sendo diferenciada pela análise da língua. Assim, compreendo que um sistema linguístico é determinado por um corpo de enunciados ou mesmo por uma coleção de fatos que ocorrem no discurso. Trata-se de construir regras para construir enunciados diferentes, ainda que dele desapareça ao longo do tempo e aborde e tenha seu restauro a partir de fragmentos. Em síntese, a língua sempre será uma formação de enunciados.

O campo dos acontecimentos discursivos, em compensação, é o conjunto sempre finito e efetivamente limitado das únicas sequências linguísticas que tenham sido formuladas: elas bem podem ser inumeráveis e podem, por sua massa, ultrapassar toda capacidade de registro, de memória ou de leitura: elas constituem, entretanto, um conjunto finito (FOUCAULT, 2008, p. 30).

Por isso, é necessário suspeitar de discursos científicos, pois muitas vezes temos que trocar nossas lentes com relação ao modo de ver o mundo. Por conseguinte, [...] "inúmeras práticas e instâncias sociais estão implicadas na produção discursiva da biologia e interessaria a nós, praticantes de estudos culturais [...]” (GUIMARÃES \& SILVA, 2009, p. 36). Assim, entendemos que os diferentes modos pelos quais se produz a ciência materializam-se por meio dos artefatos culturais (filmes, livros, documentários, entre outros).

Para Layrargues (2006, p. 1), "se o século XX teve início com o embate ideológico entre o capitalismo e socialismo, a partir do fim da guerra fria, fomos forçados a entender o capitalismo como o sistema político-ideológico vitorioso $[. .$.$] ”. Entendemos que o movimento$ ambientalista ganhou espaço para uma nova doutrina. Como resultado, não seria exagero afirmar que o início do século XXI com uma vigorosa ideia-força que defende a importância do estabelecimento de uma nova relação entre os seres humanos e a natureza, com a finalidade de reverter o quadro de degradação ambiental global, já que o próprio capitalismo pode estar sob suspeita, sendo, inclusive, apontado por muitos como um dos fatores da degradação ambiental:

Porém, é sob o denominador não tão comum, mas oficialmente acatado, o "desenvolvimento sustentável" que, de certa forma, se resumem as expectativas dessa nascente doutrina ideológica, que tem como característica, ou que procura nos fazer crer, estar distante e acima das clássicas disputas ideológicas, colocando a questão ambiental para fora do terreno político, situando-o no campo da mudança de comportamentos do ser humano, associada à conversão tecnológica na direção da ecoeficiência (LAYRARGUES, 2006, p. 1). 
Nesse contexto, podemos observar que nas últimas décadas é bastante comum o uso de termos como "sustentabilidade" ou expressões como "ética para o meio ambiente", até mesmo "identidade planetária", as quais ocorrem devido ao cenário mundial contemporâneo que visa denunciar os riscos ambientais. Para tanto, a autora afirma que:

\begin{abstract}
$\mathrm{Na}$ atualidade, a EA vem cada vez mais ganhando força e potência, estando presente em nossa vida de diversas formas diferentes, seja em ações de nosso cotidiano, como também a escolha por uma sacola retornável, economizando água, reciclando o lixo, plantando árvores; seja em ações políticas, econômicas e sociais, nas quais a questão ambiental tem sido pauta de encontros nacionais e internacionais preocupados com o futuro do Planeta (HENNING et al, 2017, p. 124).
\end{abstract}

Para Henning et al (2017, p. 125), "a natureza foi sendo tomada como um objeto a ser explorado, conhecido e alterado pelo homem. Nessa concepção, a natureza foi sendo dicotomizada do mundo da cultura", ou seja, aqui ficou entendida a maneira como foi sendo construída a lente da EA, possuindo uma visão naturalista, biológica. Com efeito, estabeleceuse uma separação entre natureza e homem.

Em outras palavras, observamos que não é um exercício fácil romper com uma visão excludente em que o homem e a natureza não estão juntos na relação entre mundo social, cultural e biológico. Assim, para Henning et al (2017, p. 126), "a EA foi se construindo e se fortalecendo através desse olhar binário, e as concepções mais tradicionais tomam o homem como o destruidor do mundo natural", por isso, nessas vertentes, há o entendimento de que a natureza pode ser recuperada pela modificação do comportamento humano.

Assim, olhar a natureza, o meio ambiente e a própria EA requer que nos coloquemos a pensar nos atravessamentos e nas relações sociais e culturais que vamos travando e que fazem parte da nossa constituição enquanto sujeitos. Aqui não há uma fórmula correta de olhar a natureza e, sim, entender que o modo como a olhamos não é neutro e muito menos individual (HENNING et al, 2017, p. 128).

Desse modo, interpretamos que o início do século XVI apresentou uma divisão de mundo, isto é: a civilização e a selvageria. O homem conhecia aquela, mas não conhecia o mundo selvagem, especialmente as terras recém-descobertas, que foram apreendidas a partir de relatos de imagens, além de enunciações verbais que foram elaborados em viagens. Para Thomas (2010), esse período foi denominado de "Predomínio humano", em que o homem era visto como o centro do mundo.

A respeito disso, Oliveira (2015) esclarece-nos que, quando o homem se referia aos animais e plantas, usava a palavra natureza, indicando o conjunto ou lugar em que os seres vivos viviam, construídos por diferentes homens, pois estes pertencem a civilização. O autor 
ainda nos diz que no Renascimento existia um duelo entre o civilizado e o natural; dessa maneira, é evidente que no contexto renascentista não havia o discurso preservacionista.

De acordo com Revel (2011), a análise arqueológica elaborada por Foucault, a partir da década de 70 , tem por objetivo a organização do conhecimento. De tal sorte, em uma época específica e com objetivos determinados para realizar a análise genealógica, deve-se reconstituir como o saber implica na relação com o conhecimento no processo de subjetivação. Assim, "a disciplinarização do mundo por meio da produção de saberes locais corresponde à disciplinarização do próprio poder: na verdade, o poder disciplinar” (REVEL, 2011, p. 134). Isso ocorre devido à disponibilização dos aparelhos de poder, como, por exemplo, os instrumentos para o acúmulo de saber e as técnicas de arquivamento.

Por conseguinte, Biguelini et al (2012, p. 75) expõem que, “com essa nova concepção, a natureza em geral não tem vida própria, nem alma ou espontaneidade, sendo composta por uma matéria física, que obedece às leis matemáticas eternas dadas por Deus”. Logo, revela-se uma concepção de natureza criada por Deus, guiando um pensamento racional e mecânico.

A partir do exposto, posso ainda observar na obra Os ossos de Descartes, de Russell Shorto, no subtítulo: “A história do esqueleto por trás do conflito entre a fé e a razão", que o conflito entre a fé e a razão estão presentes no período histórico renascentista. Compreendemos também que, nesse período, não havia discurso preservacionista, este teria um controle de espécies com a finalidade de controle econômico. Desse modo, no entendimento do século XVII, havia o enunciado de que a natureza selvagem se potencializava.

No século XVIII, por sua vez, com efeito da Revolução Industrial, foram criadas sensibilidades para a valorização dos animais, paisagens naturais e vegetais:

No século XVIII, insistia-se amplamente em que a domesticação era benéfica para os animais; ela os civilizava e aumentava seu número: "nós multiplicamos a vida, a sensação e o prazer". Vacas e ovelhas passavam melhor sob os cuidados do homem que deixadas à mercê de predadores ferozes (THOMAS, 2010, p. 25).

Como percebido, a natureza era caracterizada como dominada, pois estava sendo observada nas lentes do cartesianismo que sistematizava o pensamento. Nesse contexto do século XVIII, não havia coleta de lixo ou até mesmo saneamento básico. Os trabalhadores viviam amontoados em cortiços e passavam muitas horas trabalhando, ficando altíssima a propagação de epidemias.

Como foi exposto anteriormente, em nome dessa nova sensibilidade, a idealização da natureza passou a ser uma reserva do bem, beleza e verdade. Assim, Oliveira (2015) afirma que 
as revoluções industriais foram um marco na transição do homem na sua relação com a natureza.

Nesse cenário, o homem - que era civilizado - e a natureza, que se tornou ambiente como produção de cultura, passaram a emergir na mudança da sociedade pela produção instaurada, já que, no final do século XVIII, a natureza bela tinha a esperança da conservação do que ainda não havia sido destruído.

Sendo assim, na transição do XVIII para o XIX, observa-se que foram lançados os fundamentos da evolução. A respeito disso, Oliveira (2015) diz que foi no século XIX que a biologia como área da ciência ganhou espaço, embora muitos discursos científicos em excursões de territórios ainda não fossem conhecidos no Brasil e ficaram com mais critérios, pois estão inseridas dentro do discurso da área da botânica e da zoologia.

Fazendo uma articulação com o século XVII, verificamos que nele havia um método experimental para a natureza ser conhecida e dominada; já no século XIX, a ciência moderna instala-se nas universidades. Assim, no século XX, com a sociedade científica disseminada, ela se implanta no interior das indústrias, produzindo o modo de ver a natureza:

No século XIX, ela, a ciência moderna, já se prostra perante o mundo de forma arrogante, instala-se nas universidades, cria seus departamentos e laboratórios. As sociedades científicas se disseminam pelos continentes, a ciência se profissionaliza e surge o termo scientist para designar o status do homem que produz o conhecimento científico (CAROLA, 2010, p. 83).

Mas foi nos séculos XIX e XX que houve múltiplas invenções na ciência, como as viagens ao espaço, a criação das vacinas, guerras, crescimento da indústria bélica que geraram consequências, como a poluição do ar, do solo e da água. Logo, Oliveira (2015) afirma que foi no século XX que ocorreu a abertura de discussões sobre o ambiente relacionadas às pautas de preservação. Nesse contexto, outros enunciados para a natureza foram lançados.

Em outras palavras, compreendemos que o modo de ver e representar a Educação Ambiental, natureza e o meio ambiente relaciona-se à crise ambiental moderna. Afinal, é observado que, desde a segunda metade do século, passado a humanidade acompanha os efeitos da Revolução Industrial, ela que visa à produção, enfatizando o crescimento econômico. Desse modo, observam-se rios contaminados, poluição, bem como vazamento de produtos químicos que levaram a população e a comunidade científica a buscarem a solução para a prevenção de catástrofes. 


\section{DERMARCANDO AS FRONTEIRAS}

Na perspectiva pós-estruturalista, que visa empreender uma análise discursiva, tomamos a referência do discurso em Michel Foucault, na tentativa de desmontar os discursos sobre EA no RCA.

O RCA é um documento elaborado por uma equipe de professores da Educação Básica do Estado do Amazonas e dos municípios. Está sustentado nos pensamentos da BNCC, com uma visão neoliberal. Tem a versão preliminar no dia 02 de agosto de 2018, após isso, houve uma consulta pública pela Comissão de Implementação do Estado, no período de 06 de agosto a 06 de setembro de 2018, sendo publicada a versão final em 2019.

Segundo AMAZONAS (2019, p.19), o Referencial Curricular Amazonense (RCA) possui "a estrutura deste Referencial orienta-se a partir da BNCC, que defende o desenvolvimento dos estudantes por meio de competências e habilidades [...]", isto é, baseandose em uma formação contínua, articulando-se aos conhecimentos teóricos e cotidianos.

A análise realizada no RCA foi fundamentada no trabalho metodológico de Michel Foucault, tendo duas categorias de análise: os modos de ver e os modos de dizer a EA. Pretendemos assim realizar uma análise genealógica, que, segundo Garré \& Henning (2011, p. 235), implica que "nossa tentativa não é de descobrir quais discursos são verdadeiros ou quais são falsos", ou seja, não existe julgamento na pesquisa.

Sabemos que, no interior dos discursos, existem o jogo de verdade que engendra e produz modos de vida. Estes enunciados nos ensinam como devemos agir corretamente diante problemas ambientais.

Sendo assim, um dos desafios para o pensamento pós-estruturalista, principalmente em Foucault, foi compreender os discursos como parte indissociável da nossa própria formação como sujeitos, pois ela está presente na história e no discurso.

\section{A EDUCAÇÃO AMBIENTAL COMO MEIO PARA EDUCAR O SER HUMANO}

As lutas em torno de determinar as fronteiras da educação brasileira, sejam estas delimitações no víes tradicional crítico ou pós-crítico, acompanham a história da educação no Brasil.

$\mathrm{Na}$ esteira dos eventos sobre os cinquenta anos da ditadura militar no Brasil,

lembremos que seu final, nos anos oitenta do século XX, configurou-se como um 
período muito fecundo nas discussões sobre a educação e a organização do ensino, em especial do ensino público na perspectiva crítica e transformadora. (TOZONIREIS E CAMPOS, 2003, p. 146).

Todas as questões críticas mostram uma abordagem teórica e prática da educação que, embora tivesse muito interesse entre os educadores, não foi consolidada como hegemônica para a organização das escolas públicas de educação básica. Mas as forças hegemônicas neoliberais que atuaram na organização da sociedade brasileira nos anos 1990 foram atingindo o campo das políticas públicas da educação. Porém, as posições contra-hegemônicas avançaram nos movimentos sociais pela educação, atuando no Fórum das ONGs que elaborou o Tratado de Educação Ambiental para Sociedades Sustentáveis e Responsabilidade Global na Rio-92.

A EA pode ser considerada ao mesmo tempo agente e efeito da ambientalização das práticas sociais. Estes processos de ambientalização podem ser identificados tanto na emergência de questões e práticas ambientais como um fenômeno novo na esfera social, quanto na reconfiguração de questões, práticas e lutas tradicionais, que se transformam ao incorporar aspectos ambientais. (CARVALHO; FARIAS E PEREIRA, 2011, p. 36)

O processo de ambientalização está relacionado ao desenvolvimento da internalização da questão ambiental nas esferas sociais e na consciência dos indivíduos.

Henning et al (2018, p. 212) esclarecem que o "individualismo e consumismo são, de fato, duas características fundamentais deste tempo", isto é, na sociedade atual se busca um melhor modo de viver, como, por exemplo: a longevidade, entre outros fatores; mas a crise ambiental mostra-se como uma contrapartida.

Ainda segundo Henning et al (2018, p. 213), “o consumo exacerbado, as toneladas de lixo que soterraram a Terra e a destruição da natureza são anúncios recorrentemente tratados no interior das mídias". Em outras palavras, o enunciado nos mostra que estamos vivendo uma situação de degradação planetária, em que devemos praticar ações de preservação do planeta. De acordo com os seguintes excertos, devemos:

Justificar a importância da camada de ozônio para a vida na Terra, identificando os fatores que aumentam ou diminuem sua presença na atmosfera, e discutir propostas individuais e coletivas para sua preservação. (AMAZONAS, 2019, p. 457, grifo nosso).

Analisar e construir teias alimentares, classificando as relações ecológicas entre os seres vivos, discutindo os danos ambientais provocados pela Biopirataria, pesca e caça predatória, propondo medidas de combate por meio das leis de crimes ambientais. (AMAZONAS, 2019, p. 458, grifo nosso). 
Assim, ao abordar o enunciado EA como meio para educar o homem urbano, devemos entender que a História Ambiental e a EA estão imbricadas, pois, na área das ciências sociais e ambientais, elas se relacionam para formar uma consciência social e ecológica. Em suma, isso significa afirmar que no final do século $\mathrm{XV}$, com o advento da sociedade moderna e a consolidação do modo de vida nos séculos XVIII e XIX, presente no capitalismo, ocorreram acentuadas ações para transformar a natureza.

Podemos observar que antes mesmo do capitalismo já havia relações entre o homem e a crise ambiental:

\footnotetext{
Como consequências dessas crises ambientais, algumas civilizações desapareceram, como é o caso dos Maias na América pré-colombiana que geraram uma crise ambiental pelo uso inadequado dos elementos naturais. Na Grécia, alguns escritos de Platão apontam elementos que configurariam uma crise ambiental (ESTEVAM, 2017, p. 137).
}

Isto é, percebemos que, ao longo da história humana, a ação do homem criou impactos ambientais nos diversos períodos históricos, alterando paisagens e explorando os recursos naturais, entre outros exemplos.

Mas não foi somente a sociedade capitalista que fez alterações na natureza. Ainda segundo Estevam (2017, p. 137), “a expansão colonial europeia, o aumento populacional, o acelerado ritmo de produção e consumo [...]" geraram intensos impactos negativos para o meio ambiente, levando a perdas da biodiversidade no planeta.

Assim sendo, ao relacionarmos o sentido dos movimentos ecológicos no século XX, sendo um dos mais agitados da história humana a partir da ascensão dos movimentos sociais, Guimarães (2001, p. 4) afirma que "nos anos setenta os movimentos ecológicos emergem com ampla visibilidade nas sociedades." Ou seja, foram realizadas críticas ao modo de vida urbanoindustrial, contestado o uso de agrotóxicos, poluição das indústrias. Mas, naquele momento, os ecologistas queriam a sensibilização da população, mostrando a importância das questões educativas frente às problemáticas ambientais.

Desse modo, os movimentos ecológicos nos anos 1970 nutriam práticas para a solução dos problemas ambientais. Nisso, percebemos que eles recusaram o processo de subjetivação do capitalismo.

Segundo Guimarães (2001, p. 5), “os movimentos sociais foram constituídos a partir das significações em jogo naquela época", estando inseridos na luta dos discursos catastróficos. Dessa maneira, os discursos pedagógicos que visam à consciência, à informação e à razão, articulam-se aos discursos ecológicos que tiveram seus movimentos a partir da Era Moderna. 
Em outras palavras, isso significa entender que nos movimentos ecológicos dos anos 1990, o discurso possuía uma intenção conscientizadora e não estava mais inserido no espírito de luta social, como nos anos 1970.

Ademais, os movimentos sociais como sujeitos pedagógicos são agentes que constroem seus princípios educativos. Logo, fica claro que existem relações de poder no interior dos saberes das ações pedagógicas dos professores que são educadores ambientais. Por isso, o discurso que faz parte de tal movimento afirma que o homem produz, mas também polui, degrada e destrói a natureza. Com efeito, precisa o ser humano ser disciplinado ou educado ambientalmente. Conforme os excertos: Discutir iniciativas que contribuam para restabelecer o equilíbrio ambiental a partir
da identificação de alterações climáticas regionais e globais provocadas pela
intervenção humana. (AMAZONAS, 2019, p. 463 , grifo nosso).

Discutir em que medida a produção, a circulação e o consumo de mercadorias provocam impactos ambientais assim como influem na distribuição de riquezas, em diferentes lugares. (AMAZONAS, 2019, p. 490, grifo nosso).

Entende-se que o homem busca uma maneira de descobrir vários lugares, mas acabou modificando o mundo natural, sendo a causa de um desequilíbrio ambiental. É evidente que, no discurso ecológico, o crescimento das grandes cidades tem relação com os impactos ambientais, pois os mesmos receberam sua parcela de contribuição. Isso significa a chamada crise ambiental, como diz Henning et al $(2018$, p.5) ao afirmarem que "o consumo exacerbado, as toneladas de lixo que soterraram a Terra e a destruição da natureza são anúncios recorrentemente tratados no interior das mídias”. Logo, entendemos que fomos ensinados em vários discursos, principalmente os midiáticos, sobre a preservação da natureza. Em outras palavras, é certo afirmar que a crise ambiental faz parte das nossas vidas, mas a mídia, por exemplo, nos causa medo.

Dessa maneira, a utilização de artefatos culturais para o denominado "ecologicamente correto" mostra a cisão entre o natural e o artificial. Um exemplo se refere ao enunciado que está no documentário Trashed: Para onde vai nosso lixo, de 2011, em que se mostram resíduos sólidos como: garrafa pet, lixo hospitalar, lixo doméstico; com objetivo de alertar para a emergência dos meios de produção para o meio ambiente.

Heinning et al (2018, p. 6) esclarecem-nos ainda que "na sociedade da informação, estamos submetidos ao recorte de mundo promovido pela grande mídia, e tal abordagem adestra-nos quanto às formas mais adequadas de viver esse mundo". Isto é, somos uma 
sociedade marcada pela tecnologia, mais consumista, mas, no interior da mídia, os enunciados passam a ser como se ela fosse intocada, sobretudo nos discursos a partir dos anos 1990 .

Diante de tal cenário, deve- se "propor iniciativas individuais e coletivas para a solução de problemas ambientais da cidade ou da comunidade, com base na análise de ações de consumo consciente e de sustentabilidade bem-sucedidas" (AMAZONAS, 2019, p. 470, grifo nosso).

Assim, podemos situar essa questão do RCA, no cenário do neoliberalismo, como sendo uma expansão da lógica do mercado, formando a subjetividade política igual à economia. A respeito disso, Rosa (2019, p. 158) revela-nos que "o neoliberalismo seria uma nova razão do mundo que nos conduziu à pós-democracia", sendo um processo que, na dimensão política, tem interesses do direito privado. Outra questão é a referência para tal enunciado: por que ele enfatiza a defesa das populações indígenas ou do homem do interior?

Segundo Costa (2017), na realidade, nas áreas indígenas, houve construção de estradas, aliada à exploração da madeira, à mineração e à agropecuária, que, em vez de serem consideradas ações de destruição do meio ambiente, forem vistas, em outros períodos históricos, como avanço.

Em suma, utiliza-se de um dispositivo da sustentabilidade em que discursos econômicos articulam os seus papéis na EA e que tentam esverdear seus praticantes, ou seja, que revelam um sujeito sensível que possui novos hábitos de vida às imagens catastróficas. Tal indivíduo está relacionado aos discursos governamentais, midiáticos, escolares, entre outros.

É importante ressaltar que a EA é vista como uma orientação segundo a qual o homem é considerado um destruidor, porém, no discurso ambientalista, ele pode ser disciplinado a ser um salvador do planeta, na esteira do que afirma Costa (2017, p. 67), “o homem ora aparece como salvador ora é considerado como destruidor, mas essas posições muitas vezes dependem dos modos tidos como lícitos e ilícitos de se relacionar com a natureza."

\section{CONCLUSÃO}

A partir das premissas observadas, consideramos que podemos problematizar a ideia de EA, vista atualmente como estratégia de conversão dos estudantes, na tentativa de impor um modo de ver a natureza somente pelo viés da natureza, mas também pela visão filosófica. Isso porque, embora o RCA analisado tenha apontado regularidades, continuidades e descontinuidades $\underline{\text { em relação a EA, é recorrente a fabricação de uma natureza como fonte de serviços, selva, celeiro }}$ 
do planeta, reiterando diversas vezes o cuidado com os recursos naturais como constituinte de modos de ver e dizer uma suposta EA amazônida.

Outras materialidades também atuam na produção dessa ideia de EA. Os aplicativos, a título de exemplo, que mostram o consumo dos recursos naturais, instituindo um dito consumo ideal e correto, os editais de financiamento das agências de fomento que aprovam especialmente projetos que transmitem um aparato de comportamentos supostamente adequados.

A natureza apresentada é sempre um recurso finito, explorado, ameaçado, tocado, dependente de ações que desenvolvam a sustentabilidade e outros modos de relação dita harmônica. Desse modo, afirmamos que a produção discursiva do RCA fabrica uma EA como o saber dito responsável em formar, informar e conformar os estudantes amazônidas sobre as formas corretas de cuidar da Amazônia: não jogar lixo nos igarapés, plantar árvores, entre outras.

Portanto, a EA também está envolvida com as questões econômicas e políticas, pois o capitalismo cultural gera uma economia para as indústrias da comunicação, criando normas, regras, entre outros. Entendemos que os discursos que envolvem a problemática ambiental em nossas vidas mostram a ênfase na questão do futuro do planeta. Muitos ditos que estão no RCA revelam que devemos mudar nossas atitudes em relação ao meio ambiente.

Vale ressaltar a importância de criar outros modos de sermos sustentáveis, ou seja, mais miúdo e menos generalista, pois tal postura é múltipla, ampla, e visa agregar vários aspectos da sustentabilidade.

\section{REFERÊNCIAS}

AMAZONAS. Referencial Curricular Amazonense, 2019. Disponível em: $<$ https://www.sabermais.am.gov.br/pagina/jornada-pedagogica-2020-referencial-curricular $>$ Acesso: 05/01/2020.

BIGUELINI, C. P.; BUSSOLARO, B.; SILVA, I. O. R. Revisão do processo de desenvolvimento histórico-filosófico dos conceitos de natureza com vistas ao meio ambiente. In: Geoingá: Revista do Programa de Pós-Graduação em Geografia Maringá, v. 4, n. 1, 2012 pp. 73-88, ISSN 2175-862X (on-line). Disponível em: $<$ http://periodicos.uem.br/ojs/index.php/Geoinga/article/view/49179/751375140360> Acesso: $02 / 02 / 2020$.

CAROLA, Carlos Renato. História, Ciência e Educação Ambiental: contribuição para uma proposta educacional para sensibilidade ecológica. In: Rev. eletrônica Mestr. Educ.

Ambient. ISSN 1517-1256, v. 25, 2010, Doi: https://doi.org/10.14295/remea.v25i0.3374. Acesso: 02/02/2020. 
CARVALHO, Isabel Cristina de Moura. Educação ambiental: a formação do sujeito ecológico. $6^{\mathrm{a}}$. ed. São Paulo: Cortez, 2012.

CARVALHO, I. C. M.; FARIAS, C. R; PEREIRA, M. V. A missão “ecocivilizatória” e as moralidades ecológicas: a educação ambiental entre a norma e antinormatividade. Ambiente \& Sociedade. Campinas v. XIV, n. 2, p. 35 -49, jul.-dez. 2011. Disponível em: $<$ https://www.scielo.br/pdf/asoc/v14n2/04.pdf> Acesso: 15/01/2021.

CORAZZA, Sandra Mara. Base Nacional Comum Curricular: apontamentos críticoclínicos e um trampolim. In: Educação. Porto Alegre, v. 39, n. esp. (supl.), 2016, pp. 135144. Doi: < https://doi.org/10.15448/1981-2582.2016.s.23591 > Acesso: 27/07/2020.

COSTA, Mônica de Oliveira. A Amazônia é aqui? Redes que tecem a Amazônia discursiva no ensino de ciências. Tese - Doutorado - Universidade Federal do Pará, Instituto de Educação Matemática e Científica, Programa de Pós-Graduação em Educação em Ciências e Matemática, Belém, 2017. Disponível em:

$<$ https://www1.ufmt.br/ufmt/unidade/userfiles/publicacoes/d63839b162f23993fd0c21234411f eba.pdf > Acesso: 20/01/2020.

ESTEVAM, Bread Soares. Da crise ambiental ao despertar da consciência ecológica: Diálogos entre a História Ambiental e a Educação Ambiental. In: Revista do Lhiste, Porto Alegre, n. 6, vol. 4, 2017, 135 - 156. Disponível em:

$<$ https://seer.ufrgs.br/revistadolhiste/article/viewFile/84967/48944> Acesso: 01/07/2020.

FOUCAULT, Michel. A arqueologia do saber. 7. ed. Rio de Janeiro: Forense Universitária, 2008.

GARRÉ, Bárbara Hees; HENNING, Paula Corrêa. Problematizando a produção de alguns discursos de educação ambiental na mídia impressa: análises foucaultianas. In: Rev. eletrônica Mestr. Educ. Ambient. ISSN 1517-1256, v. 27, 2011, 1- 20. Doi: $<$ http://dx.doi.org/10.1590/0102-4698138587>.Acesso: 01/07/2020.

GUIMARÃES, Leandro Belinaso. O apelo à consciência nos movimentos ecológicos e nos movimentos por educação ambiental. In: Anped. Disponível em:

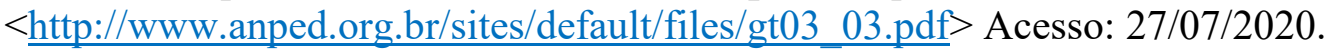

GUIMARÃES, Leandro Belinasco; SILVA, Bruna Luiza da. Planejamentos de ensino entremeando biologia e cultura. Ensino em Re-Vista, 16(1): 33-45, jan./dez. 2009.

Disponível em: $<$ http://www.seer.ufu.br/index.php/emrevista/article/download/7950/5057/>

Data de acesso: 29/ 12/2019.

HENNING, Paula Corrêa. O discurso da educação ambiental em artefatos culturais da atualidade. In: Interacções, n. 44, 2017. pp. 123-143. Doi:

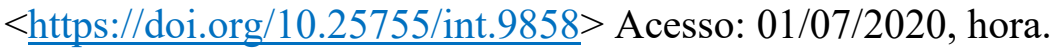

HENNING, P. C.; VEIRA, V. T.; HENNING, C. C. Crise ambiental, consumo e artefatos culturais: provocações ao tempo contemporâneo. In: EccoS - Rev. Cient., n. 45, 2018. pp. 209-220. Disponível em: 
$<$ https://periodicos.uninove.br/index.php?journal=eccos\&page=article\&op=view\&path $\% 5 \mathrm{~B} \%$ 5D=7412\&path $\% 5 \mathrm{~B} \% 5 \mathrm{D}=3740>$ Acesso: $27 / 07 / 2020$.

LAYRARGUES, Philip Pomier. Muito além da natureza: educação ambiental e reprodução social. In: LOUREIRO, Carlos (Org.), LAYRARGUES, Philippe (Org.) e CASTRO, Ronaldo (Org.). Pensamento complexo, dialética e educação ambiental. São Paulo: Cortez, 2006.

OLIVEIRA, Albaneide Cavalcante. O que é ambiente? Quando as imagens fabricam enunciados imagéticos. Dissertação (Mestrado) - Universidade Federal do Pará, Instituto de Educação Matemática e Científica, Programa de Pós-Graduação em Educação em Ciências e Matemática, Belém, 2015.

PARAÍSO, Mariucy Alves. Diferença no currículo. In: Cadernos de Pesquisa, v. 40, n. 140, 2010, pp. 587-604. Disponível em: < $\underline{\text { http://www.scielo.br/pdf/cp/v40n140/a1440140.pdf }>}$ Acesso: 02/02/2020.

REVEL, Judith. Dicionário Foucault. Tradução de Anderson Alexandre da Silva; Revisão Técnica: Michel Jean Maurice Vincent. Rio de Janeiro: Forence Universitária, 2011.

ROSA, Rafael Rocha. Neoliberalismo, desdemocratização, subjetividade. In: Argumentos, ano 11, n. 21 - Fortaleza, 2019, 154-165. Disponível em:

$<$ http://www.periodicos.ufc.br/argumentos $>$ Acesso: 27/07/2020.

TOZONI- REIS, Marília Freitas de Campos. CAMPOS, Luciane Maria Lunardi. Educação ambiental escolar, formação humana e formação de professores: articulações necessárias.

Educar em Revista, Curitiba, Brasil, Edição Especial n. 3/2014, p. 145-162. Editora UFPR. Disponível em: < https://www.scielo.br/pdf/er/nspe3/a10nspe3.pdf> Acesso: 15/01/2021.

THOMAS, Keith. $O$ homem e o mundo natural: mudanças de atitude em relação às plantas e aos animais (1500 a 1800). Tradução: João Roberto Martins Filho. $2^{\circ}$ impressão, São Paulo, Companhia das Letras, 2010.

TRASHED - Para onde vai nosso lixo. Direção de Cândida Brady. Estados Unidos: produtora executiva Rose Ganguzza, 2012.

VEIGA-NETO, Alfredo. Cultura, culturas e educação. In: Revista Brasileira de Educação, n. 23, 2013, 5 - 15. Disponível em: < http://www.scielo.br/pdf/rbedu/n23/n23a01> Acesso: $02 / 02 / 2020$. 


\section{NOTAS}

\section{AGRADECIMENTOS}

Não se aplica.

\section{FINANCIAMENTO}

Não se aplica.

\section{CONTRIBUIÇÕES DE AUTORIA}

Resumo/Abstract/Resumen: Mônica de Oliveira Costa

Introdução: Rafaella Bruno Antunes de Souza

Referencial teórico: Rafaella Bruno Antunes de Souza e Mônica de Oliveira Costa

Análise de dados: Rafaella Bruno Antunes de Souza

Discussão dos resultados: Rafaella Bruno Antunes de Souza e Mônica de Oliveira Costa

Conclusão e considerações finais: Rafaella Bruno Antunes de Souza e Mônica de Oliveira Costa

Referências: Rafaella Bruno Antunes de Souza

Revisão do manuscrito: Rafaella Bruno Antunes de Souza

Aprovação da versão final publicada: Rafaella Bruno Antunes de Souza

\section{CONFLITOS DE INTERESSE}

Declaramos não haver nenhum conflito de interesse de ordem pessoal, comercial, acadêmico, político e financeiro referente a este manuscrito.

\section{DISPONIBILIDADE DE DADOS DE PESQUISA}

O conjunto de dados que dá suporte aos resultados da pesquisa foi publicado no próprio artigo.

\section{CONSENTIMENTO DE USO DE IMAGEM}

Não se aplica.

\section{APROVAÇÃO DE COMITÊ DE ÉTICA EM PESQUISA \\ Não se aplica.}

\section{COMO CITAR - ABNT}

SOUZA, Rafaella Bruno Antunes de; COSTA, Mônica de Oliveira. Referencial Curricular Amazonense: Apontamentos sobre Educação Ambiental e possíveis transgressões. REAMEC - Rede Amazônica de Educação em Ciências e Matemática. Cuiabá, v. 9, n. 1, e21017, janeiro-abril, 2021. DOI: 10.26571/reamec.v9i1.11475.

COMO CITAR - APA

SOUZA, R. B. A. \& COSTA, M. O. (2021). Referencial Curricular Amazonense: Apontamentos sobre Educação Ambiental e possíveis transgressões. REAMEC - Rede Amazônica de Educação em Ciências e Matemática, 9 (1), e21017. DOI: 10.26571/reamec.v9i1.11475.

\section{LICENÇA DE USO}

Licenciado sob a Licença Creative Commons Attribution-NonCommercial 4.0 International (CC BY-NC 4.0). Esta licença permite compartilhar, copiar, redistribuir o manuscrito em qualquer meio ou formato. Além disso, permite adaptar, remixar, transformar e construir sobre o material, desde que seja atribuído o devido crédito de autoria e publicação inicial neste periódico.

\section{DIREITOS AUTORAIS}

Os direitos autorais são mantidos pelos autores, os quais concedem à Revista REAMEC - Rede Amazônica de Educação em Ciências e Matemática - os direitos exclusivos de primeira publicação. Os autores não serão remunerados pela publicação de trabalhos neste periódico. Os autores têm autorização para assumir contratos adicionais separadamente, para distribuição não exclusiva da versão do trabalho publicada neste periódico (ex.: publicar em repositório institucional, em site pessoal, publicar uma tradução, ou como capítulo de livro), com reconhecimento de autoria e publicação inicial neste periódico. Os editores da Revista têm o direito de proceder a ajustes textuais e de adequação às normas da publicação. 


\section{PUBLISHER}

Universidade Federal de Mato Grosso. Programa de Pós-graduação em Educação em Ciências e Matemática (PPGECEM) da Rede Amazônica de Educação em Ciências e Matemática (REAMEC). Publicação no Portal de Periódicos UFMT. As ideias expressadas neste artigo são de responsabilidade de seus autores, não representando, necessariamente, a opinião dos editores ou da referida universidade.

\section{EDITOR}

Marcel Thiago Damasceno Ribeiro

\section{HISTÓRICO}

Submetido: 29 de novembro de 2020.

Aprovado: 04 de janeiro de 2020.

Publicado: 28 de janeiro de 2021. 